\title{
Evaluation of Total Thyroidectomy for Treatment of Benign Diseases of Thyroid Gland
}

Risto Cholancheski ${ }^{*}$, Natasha Tolevska ${ }^{1}$, Ardit Qafjani ${ }^{1}$, Ilir Vela ${ }^{1}$, Borislav Kondov ${ }^{1}$, Goran Kondov ${ }^{1}$, Nexhati Jakupi ${ }^{1}$ Igor Dzikovski ${ }^{1}$, Anita Kokareva ${ }^{2}$, Mimi Srceva², Marija Tolevska², Andrijan Kartalov², Zoran Arsovski ${ }^{3}$, Andjela Vitanova ${ }^{1}$, Nina Apostolovska ${ }^{1}$

${ }^{1}$ Department of Thoracic Surgery, University Clinic for Thoracic and Vascular Surgery, Medical Faculty Skopje, Republic of Macedonia, Balkans; ' 2 epartment of Anestesiology, University Clinic for TOARILUC-KARIL, Medical Faculty Skopje, Republic of Macedonia, Balkans; ' ${ }^{2}$ Department of Pulmology, University Clinic for Pulmonology and Allergology, Medical Faculty Skopje, Republic of Macedonia, Balkans

Edited by: Sasho Stolesk Citation: Cholancheski R, Tolevska N, Qafjani A, Vela Kondov B, Kondov G, Jakupi N, Dzikovski I, Kokareva A, Srceva M, Tolevska M, Kartalov A, Arsovski Z, Vitanova A, Apostolovska N. Evaluation of Total Thyroidectomy for Treatment of Benign Diseases of Thyroid Gland. Open https://doi.org/10 3889/2amims 2020.3929 Keywords: Total thyroidectomy; Hypocalcemia;

Correspondence: Risto Cholancheski, University Clinic for Thoracic and Vascular Surgery, Medical Faculty Skopje, University of "St. Cyril and Methodius" Skopje, Mother Theresa Str. 1000, Skopje, Republic of Macedonia. Tel.: + 389-70-220-456 colanceski@hotmail.com Received: 18-Oct-2019 Accepted: $20-$-Feb-2020 opyright: ๑ 2020 Risto Cholanchesk, Natasha Tolevska, Ardit Qafjani, llir Vela, islav Kondov, Goran Kondov, Nexhati Jakup i, Igor Dzikovski, Anita Kokareva, Mimi Srceva, Marija Tolevska, Andrijan Kartalov, Zoran Arsovski, Funding: This research did not receive any financia Competing Interests: The authors have declared that competing interests exist competing interests exis Open Access: This is an open-access article distribute nommercial 4.0 International License (CC BY-NC 4.0)

\section{Abstract}

BACKGROUND: The controversy of using total thyroidectomy (TT) in treatment of benign thyroid diseases still remains controversial over the rates of complication, mostly recurrence nerve palsy and hypocalcemia, compared to non-total thyroidectomies. The latest reports in this field of research showed that that the number of complications of TT is decreasing as the skills of surgeons increase.

AIM: In this study, we reviewed 209 cases of total thyroidectomies for benign thyroid diseases where such surgery was indicated. The results were evaluated whether they support the previous reports that TT is save method of treatment of diffuse multinodular goiters, Graves' disease thyroid adenomas with diffuse goiters and thyroiditis.

METHODS: Two hundred and nine patients, 36 males and 173 females, medium age 47 (17-77) operated with TT between 2016 and 2018 were included in the evaluation study. We evaluated the: Diagnosis, indications for operation, pre-operative medication administration, laryngeal recurrent nerve palsy, hypocalcemia, hypoparathyroidism, and patohistology findings. The follow-up for hypocalcemia and laryngeal nerve palsy was performed 1 year postoperatively.

RESULTS: The age of the patients was between 17 and 77 years, medium-range 47 years old. Of 209 patients $173(83 \%)$ were female and $36(17 \%)$ male with a gender ratio of $1: 4.8$ males to females. Diagnoses before surgery were established as follows: Multinodular euthyroid goiter (MNEG) $n=106(48.80 \%)$, multinodular toxic goiter $n=12(5.74 \%)$, Graves's disease $n=6(2.87 \%)$, adenoma with multinodular goiter $n=73(34.92 \%)$, and $\mathrm{n}=16(7.65 \%)$ patients with thyroiditis. Recurrence laryngeal nerve palsy (RLNP) occurred in 6 patients $(2.87 \%)$ temporary within 3 months after the operation in 4 patients (1.92\%) and permanent palsy within 6 months and more after an operation in 2 patients $(0.95 \%)$. Voice hoarseness immediately and within 1 month after the operation was registered in 32 patients (15.3\%). RLNP and hoarseness were registered mostly in patients with pre-operative problems, mostly with extra big MNEG. One of the permanent injuries of RLN was bilateral and all others were one sided. All patients were operated with normal pre-operative vocal cord movement findings. Post-operative hypocalcemia was registered in 35 patients $(16.74 \%)$. Temporary nonsignificant hypocalcemia in $10(4.78 \%)$ temporary significant hypocalcemia in $17(8.13 \%)$, temporary severe hypocalcemia in 6 patients $(2.87 \%)$, and permanent hypocalcemia in 2 patients $(0.95 \%)$

CONCLUSION: Many studies have shown that the rate of complications is almost even for TT and NTT done for benign and malignant diseases of thyroid gland. Our data have shown that the risk of post-operative complications with TT is proportional to the number of complicated pre-operative findings of benign thyroid glands.

\section{Introduction}

The risks of surgical complications from total thyroidectomy (TT) have deterred surgeons to practice it for more than a century ago when it was introduced as a major neck surgery [1], [2], [3]. It was the problem of hormonal replacement which was the main obstacle for doing the TT. With the rise of technical and technological possibilities of surgery at the end of $20^{\text {th }}$ century, the question of doing TT arises from the need of adequate treatment if thyroid carcinoma only at the beginning of the $21^{\text {st }}$ century the question of TT for benign disease arose to the level of controversy whether is it safe and complication free, along with the development of thyroid hormone substitute thyroxin and surgical technology for safer operative techniques [4].

Furthermore, the development of more accurate diagnostic possibilities as US $\mathrm{m}$ CT, US-guided FNAB and biochemical laboratories, and radioactive scans of thyroid gland, made better accuracy of different diagnosis strict and exact differentiation of benign and malignant pathology of the thyroid gland. Although the quantity of resected thyroid gland for benign disease is still controversial, increasing number of surgeons is prone to TT for benign disease such as multinodular euthyroid goiter (MNEG), multimodal toxic goiter (MNTG), Graves's 
disease, diffuse multimodal goiter with adenomas, and single gigantic goiter [5], [6], [7]

The work of a lot of surgeons across the world has shown that complication rates of permanent recurrent laryngeal nerve palsy $0.5-3 \%$, and permanent hypoparathyroidism (HPTH) 1-2\% following subtotal thyroidectomy (STT) are similar to those following TT [8], [9].

The disadvantages of STT, treating MNEG, and MNTG are that it does not reduce the risk of persisting symptoms with a high recurrence rate of $20-50 \%$ due to gland remnants and under L-thyroxine hormone suppression treatment [10].

These recurrences require repeated surgery which increases the possibility of 20 times greater risk of complications such as hypo parathyroidectomy and laryngeal recurrent nerve palsy (LRNP).

TT shortly eliminates the possibility of recurrent disease of the thyroid gland for MNTG and Graves' disease and with the accurate hormonal replacement with L-thyroxine it is relatively easy to achieve a better outcome of treating MNTG, Graves' disease and mixed thyroid adenomas, diffuse MNEG and MNTG, thyroiditis.

Still, no surgeon in the world can exactly sit where to cut the thyroid gland when it is diffusely nodulated.

For the past decade, a lot of papers have been published claiming excellent results with almost no complications with TT for benign disease. There is a general conclusion that TT is efficient and proved to be the first choice of surgery for benign thyroid diseases such as MNG euthyroid or toxic, Graves' disease MDA with diffuse MNG, and diffuse thyroiditis.

The aim of thins paper is to evaluate whether TT can be carried out with low complication rates as low as a similar result in comparison to other proven surgery units.

\section{Methods}

We have performed a retrospective study of 209 patients who underwent TT from 2015 to 2018 at the University Clinic of Thoracic Surgery Mother Theresa in Skopje, Republic of Macedonia.

We extracted data of sex, age, thyroid disease details, pre- and post-operative evaluation of recurrent laryngeal nerve palsy (RLNP) rates, HPTH rates, patohistological findings, and surgery complication rates.

The patients with thyroid carcinoma were excluded from the study.

\section{Pre-operative management}

Clinical diagnosis in all patients included measurement of serum thyroxin T4, three iodine thyroxin T3, thyrotropin, thyroid antibodies, calcium serum levels, ultrasound US morphology, and SPECT scan with technetium-99m. A computed tomography scan of the neck was indicated for big retrosternal and thyroid glands with unclear morphology. Thyrosupresant therapy and beta-blockers therapy were indicated a month before the operative date for regulated toxic goiters and Graves' disease.

\section{Inclusion diagnosis}

MNGT, MNGE, adenomas of the thyroid gland with diffuse MNG, Graves' disease, and diffuse thyroiditis with suspicious solitary nodules with FBAV BETHESDA III and lower.

\section{Surgical management}

Dissection of the thyroid gland after suprajugular incision with muscle preservation, resection of the gland after lymph node LN, and parathyroid gland preservation using US FORCE TRIAD scissor and ULTRACISION ETHICON scissors with ligation of the inferior thyroid artery. Drainage of the neck was performed within $24 \mathrm{~h}$. Discharging of the patient was on $3^{\text {rd }}$ day after the surgery.

\section{Post-operative measurement}

Total serum calcium levels twice a day considering hypocalcemia as a Ca level $\leq 2,0 \mathrm{mmol} / \mathrm{L}$.

Considering temporary hypocalcemia in patients without symptoms, Ca level $\leq 2.0 \mathrm{mmol} / / / 2$ days.

Temporary hypocalcemia with symptoms in patients with $\mathrm{Ca}$ level $\leq 2.0 \mathrm{mmol} / \mathrm{l} / 2$ days needing supplementary $3 \times 20 \mathrm{mg}$ of $\mathrm{Ca}$ gluconate more than 3 day.

Temporary hypocalcemia with Ca level $\leq 2.0$ $\mathrm{mmol} / \mathrm{l}$ until the first control, which needed a supplement of Calcium $3 \times 1 \mathrm{~g} /$ day tablets.

Temporary hypocalcemia with symptoms in patients $\mathrm{Ca}$ level $\leq 2.0 \mathrm{mmol} / \mathrm{l}$. Three weeks after surgery needing $1 \times 1 \mathrm{~g} /$ day supplementary calcium therapy in a period of 3 months.

Temporary hypocalcemia with symptoms $\mathrm{Ca}$ level $\leq 2.0 \mathrm{mmol} / \mathrm{l} 6$ weeks after surgery and treated with D Vitamin solution 5000 i.u.

After 6 months of hypocalcemia with symptoms, we consider this as a state of permanent hypocalcemia.

The condition of LRN laryngeal recurrent nerve was passively evaluated by vocal cords movement immediately after extubation with video laryngoscopy 
and in case of stridor and ENT evaluation with video laryngoscopy for nerve palsy.

After getting negative histology for malignant disease within 5 days, L-thyroxine was administered in a starting dose of $25-\mathrm{mg} /$ day.

The follow-up of the patient was conducted in collaboration with endocrinologist, internist, and ENT if needed after 1 week, 1 month, 3 months, and 1 year after the operation.

The patients were evaluated for eventual hypocalcemia and for supplementation Ca and Vitamin D3.

LNP was evaluated by the ENT doctor after 6 months of voice hoarseness and aphonia of the patients.

\section{Results}

Two hundred nine patients with benign thyroid disease were surgically treated with TT at the University Clinic for Thoracic Surgery Mother Theresa - Skopje, between January 2015 and December 2018. The distribution of the patients through the years is shown in Table 1.

Table 1: Distribution of the patients

\begin{tabular}{ll}
\hline Years & $\mathrm{n}=$ patients \\
\hline 2015 & 45 \\
2016 & 46 \\
2017 & 54 \\
2018 & 64 \\
Total & 209 \\
\hline
\end{tabular}

The age of the patients was between 17 and 77 years, medium-range 47 years old.

Of 209 patients, 173 (83\%) were female and $36(17 \%)$ male with a gender ratio of $1: 4.8$ males to females.

Diagnoses before surgery were established as follows: MNEG $n=106$ (48.80\%), MNTG multinodular toxic goiter (MNTG) n = $12(5.74 \%)$, Graves's disease $n$ $=6(2.87 \%)$, adenoma with multinodular goiter (AMNG) $\mathrm{n}=73(34.92 \%)$, and $\mathrm{n}=16(7.65 \%)$ patients with thyreoiditis. All of the patient diagnoses were established by the endocrinologist and internal medicine doctors at Clinic for Endocrinology and Institute for Nuclear Medicine at Medical Faculty in Skopje.

The indication for surgical treatment was established by the surgeon in collaboration with endocrinologist and internist doctors who manage the diagnosis for surgical treatments. About $54 \%$ of the surgically treated patients have no pre-operative problems at the referral to surgery and most of them were with multinodular bilateral diffuse goiters while the other $46 \%$ were preoperatively marked like other who had operative indication due to ventilatory problems, swallowing problems, tracheomalacia, and pressure to the surroundings of the thyroid gland.

The 18 patients with multinodular toxic goiters and Graves' disease (8.61\%) were preoperatively treated with antithyroid therapy 7 (38.88\%) and $11(61.12 \%)$ with antithyroid therapy and b-blockers therapy and were operated after the relapse of high thyroxin values, hyperthyroidism after medicamentos therapy.

RLNP occurred in 6 patients (2.87\%), temporary within 3 months after the operation in 4 patients (1.92\%), and permanent palsy within 6 months and more after operation in 2 patients $(0.95 \%)$. Voice hoarseness immediately and within 1 month after the operation was registered in 32 patients (15.3\%). RLNP and hoarseness were registered mostly in patients with preoperative problems, mostly with extra big MNEG. One of the permanent injuries of RLN was bilateral and all others were one sided. All patients were operated with normal pre-operative vocal cord movement findings.

Post-operative hypocalcemia was registered in 35 patients $(16.74 \%)$. Temporary non-significant hypocalcemia in $10(4.78 \%)$, temporary significant hypocalcemia in $17(8.13 \%)$, temporary severe hypocalcemia in 6 patients $(2.87 \%)$, and permanent hypocalcemia in 2 patients $(0.95 \%)$.

Furthermore, temporary non-significant and severe hypocalcemia were registered more in patients surgically treated for MNEG and AMNG, while hyperparathyroidism with permanent hypocalcemia was registered in patients with Graves's disease.

Post-operative complications as hemorrhage was finding in 2 patients ant no mortality was registered in Table 2.

\section{Table 2: Complications after total thyroidectomy}

\begin{tabular}{ll}
\hline Type of hypocalcemia & No of patients \\
\hline Hypocalcemia total & $35(16.74 \%)$ \\
Temporary non-significant & $10(4.78 \%)$ \\
Temporary significant & $17(2.87 \%)$ \\
Temporary severe & $6(0.95 \%)$ \\
Permanent & $2(0.95 \%)$ \\
Recurrent laryngeal nerve palsy & \\
Temporary & $4(1.92 \%)$ \\
Permanent & $2(0.95 \%)$ \\
Hoarseness & $32(15.3 \%)$ \\
Bleeding & $2(0.95 \%)$ \\
\hline
\end{tabular}

Patohistology results were carried out in all patients, with 102 multinodular diffuse common goiters, MNTG 8, and MNTG with adenoma 4, Graves' disease 6 , thyroiditis Hashimoto 17, and adenoma of the thyroid gland with multifocal diffuse goiter 73, atypical cell adenoma $7(9.59 \%)$, Hurthle cell adenoma 36 (49.31\%), and papillary adenoma 30 (41.1\%) (Table 3).

After a year follow-up of the patients at 1, 3, 6 , and 12 months postoperatively, no recurrence was observed and all patients were euthyroid with L-thyroxin treatment of supplementation.

The normal range of total calcium level was found in most of the patients, Ca 2.2-2.7 mmol/L. Severe 
Table 3: Patohistology findings

\begin{tabular}{ll}
\hline Histology & No of patients \\
\hline Multinodular diffuse goiters euthyroid & 102 \\
Multinodular diffuse goiters & 12 \\
Diffuse & 8 \\
Adenomas & 4 \\
Graves's disease & 6 \\
Multinodular diffuse goiters+adenomas & 73 \\
Atypical cell & $7(9.59 \%)$ \\
Hurthle cell & $36(49.31 \%)$ \\
Papillary adenoma & $30(41.1 \%)$ \\
Thyroiditis Hashimoto & $17(7.65 \%)$ \\
\hline
\end{tabular}

hypocalcemia, which occurred in 6 patients, resolved within 6 months with total $\mathrm{Ca}$ levels vary between 1.7 and $2.1 \mathrm{mmol} / \mathrm{L}$, treated with calcium 2-3.0 g. Ca-carbonate tablets/day and 5000 i.u. Vitamin D3/day and 2 patients have rest with permanent hypocalcemia more than 6 months until 1 year with total calcium levels between 1.7 and $2.0 \mathrm{mmol} / \mathrm{L}$ and were treated with Ca-carbonate tablets $2.0 \mathrm{~g} /$ day and Vitamin D3 5000 i.u./day for a year.

\section{Discussion}

Until the retrieval of L-thyroxine, it was almost impossible to do TT except "out of need," for gigantic obstructive goiters and carcinomas [11].

After the introduction of hormonal replacement and improvement of surgical techniques, the TT becomes possible at the end of the $21^{\text {st }}$ century [12].

Although the procedure remains controversial, it is increasingly routinely performed for benign thyroid disease as for thyroid carcinomas [13].

The indication for TT arises from a logical fact that even accepted as benign MNGE, MNGT, and TA with diffuse MNG; GD is diffuse diseases of the thyroid gland, for who is impossible to say what part to be left in operation simply because there is no strict margin of the pathological changes of the gland itself [14].

We strongly believe and recommend TT for benign disease because of nonpossibility of recurrent disease, especially for diffuse MNG of the two lobes, GD and TA, with diffuse MNG of the rest tissue [15].

It is increasingly recognized that TT is appropriate for surgical treatment of BMNG $T+E$ particularly when both lobes are involved [16].

The advantages of TT are release of symptoms, possibility of definitive histological finding, especially in suspicious cases of possible malignancy [17].

Reports say that there is a risk of $5-10 \%$ of malignancy to be found by incidence in MNG [18].

On the other side, the report of STT or unilateral thyroidectomy as a procedure with leaving residual glandular tissue, which exposes the patients to $20-40 \%$ risk of recurrent disease, which leads to repeated surgery, and which increases the possibility of complication [19].

The notorious fact is that the risk of surgical post-operative complication of non-TT is similar to that of TT and the risk of reoperation is 20 times bigger with non-TT [20].

The complication incidents (HPTH and RLNP) of TT have been reported high in some studies, where on the other side, there have been studies that report the low incident.

Low rates of complications have been reported in similar studies [21].

Furthermore, in the past two decades many reports have shown no significant difference in complication rates among patients who underwent TT compared with those who underwent non-total thyroidectomy (NTT) [22].

The percentage of complications seems to depend of the readiness and competence of the surgeon performing TT [23].

The number of TT in recent years has increased based on many research which slowly but surely has proven that new surgical techniques and technologies can increase surgeons capacity of safe TT.

In our study data suggests that the number of operated TT is increasing through the years. The age and gender frequencies are similar to those reported in literature and also the distribution of diagnoses for TT is similar to those reported in literature [24].

The relatively bigger number of LRNP and hypocalcemia in a patient operated with TT is due to a bigger percentage $-46 \%$ of indications marked as others, where the most significant reason for possible post-operative complications, after TT, is the late referral of the patients to the surgery unit with more pre-operative complications such as: Giganteus goiters, pressure to the adjacent structures in the neck, tracheomalacia, and problems arising from changed neck anatomy [25].

The distribution of RLNP, hypocalcemia, and patohistological findings is similar to the cited authors in the literature.

\section{Conclusion}

Having in mind that data from a number of studies across the world and from our own experience show that TT can be carried out safely with a low complication rate.

In recent studies, it is more obvious that the rate of complications of TT for benign thyroid disease is decreasing as surgeons skills increase as years go 
by the percentage of complication rates is obviously decreasing in many reports.

Many studies have shown that the rate of complications is almost even for TT and NTT done for benign and malignant diseases of thyroid gland.

Our data have shown that the risk of postoperative complications with TT is proportional to the number of complicated pre-operative findings of benign thyroid glands.

L-thyroxin is a good supplement for achieving euthyroid condition after TT.

\section{References}

1. Gough IR, Wilkinson D. Total thyroidectomy for management of thyroid disease. World J Surg. 2000;24(8):962-5. https://doi. org/10.1002/bjs. 4507

PMid:10865041

2. Bron LP, O'Brien CJ. Total thyroidectomy for clinically benign disease of the thyroid gland. Br J Surg. 2004;91(5):569-74. PMid: 15122607

3. Pattou F, Combemale F, Fabre S, Carnaille B, Decoulx M, Wemeau JL, et al. Hypocalcaemia following thyroid surgery: Incidence and prediction of outcome. World J Surg. 1998;22(7):718-24 PMid:9606288

4. Gough IR. Total thyroidectomy: Indications, technique and training. Aust N Z J Surg. 1992;62(2):87-9.

PMid:1586310

5. Delbridge L, Guinea Al, Reeve TS. Total thyroidectomy for bilateral benign multinodular goiter: Effect of changing practice. Arch Surg. 1999;134(12):1389-93. https://doi.org/10.1001/ archsurg.134.12.1389

6. De Roy van Zuidewijn DB, Songun I, Kievit J, van de Velde CJ. Complications of thyroid surgery. Ann Surg Oncol. 1995;2(1):5660. https://doi.org/10.1007/bf02303703

PMid:7834455

7. Younes N, Robinson B, Delbridge L. The aetiology, investigation and management of surgical disorders of the thyroid gland. Aust N Z J Surg. 1996;66(7):481-90. https://doi. org/10.1111/j.1445-2197.1996.tb00787.x PMid:8678880

8. Phillips AW, Fenwick JD, Mallick UK, Perros P. The impact of clinical guidelines on surgical management in patients with thyroid cancer. Clin Oncol (R Coll Radiol). 2003;15(8):485-9. https://doi.org/10.1016/s0936-6555(03)00195-x PMid:14690005

9. Beenken S, Roye D, Weiss H, Sellers M, Urist M, Diethelm A, et al. Extend of surgery for intermediate-risk well-differentiated thyroid cancer. Am J Surg. 2000;179(1):51-6. PMid:10737579

10. Friguglietti CU, Lin CS, Kulcsar MA. Total thyroidectomy for benign thyroid disease. Laryngoscope. 2003;113(10):1820-6. https://doi.org/10.1097/00005537-200310000-00030 PMid:14520113

11. $\mathrm{Hu} \mathrm{J}$, Zhao N. Total thyroidectomy as primary surgical management for thyroid disease: Surgical therapy experience from 5559 thyroidectomies in a less-developed region. World $\mathrm{J}$ Surg Oncol. 2016;14(1):20.

PMid:26801233

12. Sultan HM, Ahmed HA, Sedhom HI. Evaluation of total thyroidectomy in benign thyroid diseases. Menoufia Med J. 2014;27(1):205-7. https://doi.org/10.4103/1110-2098.132807

13. Bellantone R, Lombard CP. Total thyroidectomy for management of benign thyroid disease: Review of 526 cases. World J Surg. 2002;26(12):1468-71.

PMid: 12360381

14. Di Donna V.Anew strategy to estimate levothyroxine requirement after total thyroidectomy for benign thyroid disease. Thyroid. 2014;24(12):1759-64. https://doi.org/10.1089/thy.2014.0111 PMid:25268754

15. Toluee M, Hedayati-Emami MH, Barzegar-Savasari MR, Shahrousvand Y, Mobayen MR. Treatment outcome of total thyroidectomy for multinodular goiter. Zahedan J Res Med Sci. 2015;17(8):e1026. https://doi.org/10.17795/zjrms1026

16. Iddings $\mathrm{D}$. Comparison of complications of total thyroidectomy in malignant vs. benign thyroid tumors. J Clin Oncol. 2008;26 Suppl 15:17012-2. https://doi.org/10.1200/jco.2008.26.15_suppl.17012

17. Delbridge L. Total thyroidectomy: The evolution of surgical technique. ANZ J Surg. 2003;73(9):761-8. https://doi. org/10.1046/j.1445-2197.2003.02756.x PMid: 12956795

18. Wheeler $\mathrm{MH}$. Total thyroidectomy for benign thyroid disease. Lancet. 1998;351(9115):1526-7. https://doi.org/10.1016/ s0140-6736(05)61116-6

PMid:10326531

19. Barczyński M, Konturek A, Hubalewska-Dydejczyk A. Five-year follow-up of a randomized clinical trial of total thyroidectomy versus Dunhill operation versus bilateral subtotal thyroidectomy for multinodular nontoxic goiter. World J Surg. 2010;34(6):120313. https://doi.org/10.1007/s00268-010-0491-7 PMid:20174803

20. Vassiliou I, Tympa A. Total thyroidectomy as the single surgical option for benign and malignant thyroid disease: A surgical challenge. Arch Med Sci. 2013;9(1):74-8. https://doi. org/10.5114/aoms.2013.33065

PMid:23515861

21. Ram BR, Goud VS, Kumar DR, Venkanna M. Total thyroidectomy for benign thyroid disease: A prospective study. Int J Sci Stud. 2016;4(1):161-4.

22. Liu $Q$, Djuricin $G$, Prinz RA. Total thyroidectomy for benign thyroid disease. Surgery. 1998;123(1):2-7. https://doi.org/10.1016/ s0039-6060(98)70221-1

PMid:9457216

23. Agarwal G, Aggarwal V. Is total thyroidectomy the surgica procedure of choice for benign multinodular goiter? An evidencebased review. World J Surg. 2008;32(7):1313-24. https://doi. org/10.1007/s00268-008-9579-8

PMid:18449595

24. Colak T, Akca T, Kanik A, Yapici D, Aydin S. Total versus subtotal thyroidectomy for the management of benign multinodular goiter in an endemic region. ANZ J Surg 2004;74(11):974-8. https:// doi.org/10.1111/j.1445-1433.2004.03139.x

PMid: 15550086

25. Efremidou El, Papageorgiou MS, Liratzopoulos N, Manolas KJ. The efficacy and safety of total thyroidectomy in the management of benign thyroid disease: A review of 932 cases. Can J Surg. 2009;52(1):39-44.

PMid:19234650 